\title{
Anti-1-Amino-3-18 F-Fluorocyclobutane-1-Carboxylic Acid: Physiologic Uptake Patterns, Incidental Findings, and Variants That May Simulate Disease
}

\author{
David M. Schuster ${ }^{1}$, Cristina Nanni ${ }^{2}$, Stefano Fanti ${ }^{2}$, Shuntaro Oka ${ }^{3}$, Hiroyuki Okudaira ${ }^{3}$, Yusuke Inoue ${ }^{4}$, Jens Sörensen ${ }^{5}$, \\ Rikard Owenius $^{6}$, Peter Choyke ${ }^{7}$, Baris Turkbey ${ }^{7}$, Trond V. Bogsrud ${ }^{8,9}$, Tore Bach-Gansmo ${ }^{8}$, Raghuveer K. Halkar ${ }^{1}$, \\ Jonathon A. Nye ${ }^{1}$, Oluwaseun A. Odewole ${ }^{1}$, Bital Savir-Baruch ${ }^{1}$, and Mark M. Goodman ${ }^{1}$ \\ ${ }^{1}$ Department of Radiology and Imaging Sciences, Emory University, Atlanta, Georgia; ${ }^{2}$ Department of Nuclear Medicine, Policlinico \\ S. Orsola, University of Bologna, Bologna, Italy; ${ }^{3}$ Research Center, Nihon Medi-Physics Co., Ltd., Chiba, Japan; ${ }^{4}$ Department of \\ Diagnostic Radiology, Kitasato University School of Medicine, Kitasato, Japan; ${ }^{5}$ Department of Radiology, Oncology and Radiation \\ Sciences, Uppsala University, Uppsala, Sweden; ${ }^{6}$ GE Healthcare, Life Sciences, Imaging R\&D, Uppsala, Sweden; ${ }^{7}$ Molecular \\ Imaging Program, National Cancer Institute, Bethesda, Maryland; ${ }^{8}$ Department of Radiology and Nuclear Medicine, Oslo University \\ Hospital, Oslo, Norway; and ${ }^{9}$ Department of Nuclear Medicine and PET-Center, Aarhus University Hospital, Aarhus, Denmark
}

Anti-1-amino-3-18 F-fluorocyclobutane-1-carboxylic acid ( $\left.{ }^{18} \mathrm{~F}-\mathrm{FACBC}\right)$ is a synthetic amino acid analog PET radiotracer undergoing clinical trials for the evaluation of prostate and other cancers. We aimed to describe common physiologic uptake patterns, incidental findings, and variants in patients who had undergone ${ }^{18} \mathrm{~F}-\mathrm{FACBC} \mathrm{PET}$. Methods: Sixteen clinical trials involving $611^{18} \mathrm{~F}-\mathrm{FACBC}$ studies from 6 centers, which included dosimetry studies on 12 healthy volunteers, were reviewed. Qualitative observations of common physiologic patterns, incidental uptake, and variants that could simulate disease were recorded and compared with similar observations in studies of the healthy volunteers. Quantitative analysis of select data and review of prior published reports and observations were also made. Results: The liver and pancreas demonstrated the most intense uptake. Moderate salivary and pituitary uptake and variable mild to moderate bowel activity were commonly visualized. Moderate bone marrow and mild muscle activity were present on early images, with marrow activity decreasing and muscle activity increasing with time. Brain and lungs demonstrated activity less than blood pool. Though ${ }^{18}$ F-FACBC exhibited little renal excretion or bladder uptake during the clinically useful early imaging time window, mild to moderate activity might accumulate in the bladder and interfere with evaluation of adjacent prostate bed and seminal vesicles in $5 \%-10 \%$ of patients. Uptake might also occur from benign processes such as infection, inflammation, prostatic hyperplasia, and metabolically active benign bone lesions such as osteoid osteoma. Conclusion: Common physiologic uptake patterns were similar to those noted in healthy volunteers. The activity in organs followed the presence of amino acid transport and metabolism described with other amino acid-based PET radiotracers. As with other PET radiotracers such as ${ }^{18} \mathrm{~F}-\mathrm{FDG}$, focal nonphysiologic uptake may represent incidental malignancy. Uptake due to benign etiologies distinct from physiologic background also occurred and could lead to misinterpretations if the reader is unaware of them.

Received May 24, 2014; revision accepted Oct. 3, 2014.

For correspondence contact: David M. Schuster, Division of Nuclear Medicine and Molecular Imaging, Department of Radiology and Imaging Sciences, Emory University Hospital, Room E152, 1364 Clifton Rd., Atlanta, GA 30322

E-mail: dschust@emory.edu

Published online Nov. 11, 2014.

COPYRIGHT (C 2014 by the Society of Nuclear Medicine and Molecular Imaging, Inc.
Key Words: ${ }^{18} \mathrm{~F}-\mathrm{FACBC}$; physiologic uptake; positron emission tomography

J Nucl Med 2014; 55:1986-1992

DOI: 10.2967/jnumed.114.143628

\section{A} mino acids are involved in a variety of biologic processes including protein synthesis, and amino acid transport is upregulated in many neoplasms (1-4). Consequently, radiolabeled amino acids, both natural and synthetic, have been used for oncologic molecular imaging.

Anti-1-amino-3- ${ }^{18} \mathrm{~F}$-fluorocyclobutane-1-carboxylic acid $\left({ }^{18} \mathrm{~F}\right.$ FACBC) is an investigational synthetic nonmetabolized amino acid analog PET radiotracer (5-14). Transport is primarily mediated by sodium-dependent amino acid transporters, specifically system ASC, with contribution by sodium-independent system L $(15,16)$. Though this PET radiotracer has been most actively studied in patients with prostate carcinoma, other trials have been completed or are under way, including those for cerebral gliomas and breast, lung, and head and neck cancers, among others.

For well-established radiotracers such as ${ }^{18} \mathrm{~F}-\mathrm{FDG}$, normal uptake and variants have been reported (17-19). However for ${ }^{18} \mathrm{~F}-\mathrm{FACBC}$, biodistribution and radiation dosimetry have been obtained only in small sets of healthy volunteers $(9,20,21)$. At our institutions, we have also obtained ${ }^{18} \mathrm{~F}-\mathrm{FACBC}$ scans in clinical trials involving prostate cancer and other neoplasms. The purpose of this study was to report our collective experience with ${ }^{18} \mathrm{~F}-\mathrm{FACBC}$ imaging in patients enrolled in clinical trials, correlating uptake patterns to those of healthy volunteers in the description of common physiologic uptake, incidental findings, and variants that may simulate disease.

\section{MATERIALS AND METHODS}

Study Protocols and Demographics

The ${ }^{18}$ F-FACBC studies of 598 subjects, including 12 healthy volunteers (23 women and 575 men; 611 total scans; 13 patients with repeated studies), spanning from October 16, 1996, to February 10, 
2014, at 6 institutions were qualitatively reviewed at each site. Table 1 lists the protocols under which the patients received the ${ }^{18} \mathrm{~F}-\mathrm{FACBC}$ scan. Imaging was acquired for all studies, commencing approximately $1-5$ min after radiotracer injection. All study protocols were approved by the local Institutional Review Board or Committee on Ethics or equivalent in accordance with the principles of the Declaration of Helsinki and with national regulations. Written informed consent was obtained from all enrolled subjects.

TABLE 1

Clinical Trial Studies Reviewed

\begin{tabular}{|c|c|c|c|c|c|c|}
\hline Study & $\begin{array}{l}\text { No. of } \\
\text { patients }\end{array}$ & Activity (MBq) & Extent of scan & Technique & Mean age (y) & Sex \\
\hline Emory initial pilot & 18 & $292.3(99.9)$ & $\begin{array}{l}\text { Skull vertex to } \\
\text { thighs }\end{array}$ & $\begin{array}{l}\text { 60-min dynamic brain } \\
\text { (followed by whole-body } \\
\text { imaging) }\end{array}$ & $53.8(9.3)$ & $\begin{array}{l}\text { Male, 12; } \\
\quad \text { female, } 6\end{array}$ \\
\hline Emory dosimetry & 6 & $366.6(51.0)$ & $\begin{array}{l}\text { Skull vertex to } \\
\text { thighs }\end{array}$ & $\begin{array}{l}6 \text { sets of serial static scans } \\
\text { for } 120 \mathrm{~min}\end{array}$ & $48(15.0)$ & $\begin{array}{l}\text { Male, 3; } \\
\quad \text { female, } 3\end{array}$ \\
\hline Emory prostate pilot & 15 & $372.6(22.9)$ & Abdomen/pelvis & $\begin{array}{l}\text { 65-min dynamic pelvis } \\
\text { (followed by } \\
\text { abdomen/pelvis) }\end{array}$ & $62.0(8.8)$ & Male, 15 \\
\hline Emory renal pilot & 6 & $388.5(14.1)$ & Abdomen & $\begin{array}{l}\text { 120-min dynamic } \\
\text { renal-level abdomen }\end{array}$ & $67.3(15.1)$ & $\begin{array}{l}\text { Male, } 5 ; \\
\quad \text { female, } 1\end{array}$ \\
\hline Emory lung pilot & 10 & $313.5(76.7)$ & Chest & $\begin{array}{l}\text { 45-min dynamic } \\
\text { lesion-level chest }\end{array}$ & $66.4(12.8)$ & $\begin{array}{l}\text { Male, 3; } \\
\quad \text { female, } 7\end{array}$ \\
\hline $\begin{array}{l}\text { Emory recurrent } \\
\text { prostate cancer }\end{array}$ & $\begin{array}{l}128 \text { scans } \\
\text { in } 115 \\
\text { patients }\end{array}$ & $358.9(51.8)$ & Abdomen/pelvis & $\begin{array}{l}\text { 60-min sequential } \\
\text { multiphase } \\
\text { abdomen/pelvis }\end{array}$ & $67.3(7.6)$ & Male, 128 \\
\hline $\begin{array}{l}\text { Emory primary } \\
\text { prostate cancer }\end{array}$ & 11 & $347.8(81.4)$ & Pelvis & $60-$ min dynamic pelvis & $60.8(6.3)$ & Male, 11 \\
\hline Emory breast pilot & 3 & $360.0(14.1)$ & Chest & $\begin{array}{l}\text { 45-min dynamic breast } \\
\text { level }\end{array}$ & $60(8.9)$ & Female, 3 \\
\hline Emory parathyroid & 3 & $351.5(34.0)$ & Neck & $\begin{array}{l}\text { 60-min sequential } \\
\text { multiphase neck/upper } \\
\text { chest }\end{array}$ & $60.3(6.4)$ & $\begin{array}{l}\text { Male, } 1 ; \\
\quad \text { female, } 2\end{array}$ \\
\hline $\begin{array}{l}\text { Emory recurrent } \\
\text { prostate cancer } \\
\text { outcomes }\end{array}$ & 13 & $367.0(15.5)$ & Abdomen/pelvis & $\begin{array}{l}\text { 30-min sequential } \\
\text { multiphase } \\
\text { abdomen/pelvis }\end{array}$ & $61.5(9.2)$ & Male, 13 \\
\hline $\begin{array}{l}\text { Emory PET and MR } \\
\text { recurrent prostate } \\
\text { cancer }\end{array}$ & 6 & $373.7(9.4)$ & Abdomen/pelvis & $\begin{array}{l}\text { 30-min sequential } \\
\text { multiphase } \\
\text { abdomen/pelvis }\end{array}$ & $69(5.1)$ & Male, 6 \\
\hline $\begin{array}{l}\text { Bologna recurrent } \\
\text { prostate cancer }\end{array}$ & 61 & $379(12.1)$ & $\begin{array}{l}\text { Skull vertex to } \\
\text { thighs }\end{array}$ & $\begin{array}{l}\text { Single static scan starting } \\
\text { at thighs }\end{array}$ & $67.8(6.5)$ & Male, 61 \\
\hline $\begin{array}{l}\text { Kitasato phase one } \\
\text { dosimetry }\end{array}$ & 6 & $195.0(10.3)$ & $\begin{array}{l}\text { Skull vertex to } \\
\text { thighs }\end{array}$ & $\begin{array}{l}11 \text { series of whole-body } \\
\text { PET scans during } 3 \\
\text { sessions of } 0-90, \\
150-170 \text {, and } \\
220-240 \text { min }\end{array}$ & $24(3.0)$ & Male, 6 \\
\hline $\begin{array}{l}\text { Uppsala phase one } \\
\text { primary prostate } \\
\text { cancer }\end{array}$ & 6 & $418(10.0)$ & Pelvis & $\begin{array}{l}90 \text { (optional } 120 \text { )-min } \\
\text { dynamic pelvis }\end{array}$ & $67(5.0)$ & Male, 6 \\
\hline $\begin{array}{l}\text { NIH primary prostate } \\
\text { cancer }\end{array}$ & 21 & $351.5(9.0)$ & $\begin{array}{l}\text { Pelvis/lower } \\
\text { abdomen } \\
\text { dynamic, } \\
\text { whole-body } \\
\text { static at end }\end{array}$ & $\begin{array}{l}\text { 30-min dynamic pelvis, } \\
\text { then 10-min dynamic } \\
\text { lower abdomen } \\
\text { (followed by static } \\
\text { whole body) }\end{array}$ & $62(6.5)$ & Male, 21 \\
\hline $\begin{array}{l}\text { Oslo University } \\
\text { Hospital prostate } \\
\text { and other cancers }\end{array}$ & 298 & $296(56.0)$ & $\begin{array}{l}\text { Skull vertex to } \\
\text { thighs }\end{array}$ & $\begin{array}{l}\text { Single static scan } \\
\text { starting at thighs }\end{array}$ & $66.0(6.4)$ & $\begin{array}{l}\text { Male, } 297 \\
\quad \text { female, } 1\end{array}$ \\
\hline
\end{tabular}


TABLE 2

Select Organ SUV mean with Absolute and Relative Bladder Activity in 128-Study Cohort

\begin{tabular}{|c|c|c|c|c|c|c|c|c|c|c|}
\hline \multirow[b]{2}{*}{ Time (min) } & \multirow[b]{2}{*}{ Bladder SUV $V_{\text {mean }}$} & \multirow{2}{*}{$\begin{array}{l}\text { Blood-pool } \\
\text { (aorta) SUV }\end{array}$} & \multirow{2}{*}{$\begin{array}{l}\text { Marrow (L3) } \\
\text { SUV }_{\text {mean }}\end{array}$} & \multirow[b]{2}{*}{ Liver $\mathrm{SUV}_{\text {mean }}$} & \multicolumn{2}{|c|}{$\begin{array}{l}\text { Bladder } \geq \\
\text { blood-pool } \\
\text { SUV }_{\text {mean }}\end{array}$} & \multicolumn{2}{|c|}{$\begin{array}{c}\text { Bladder } \geq \\
\text { marrow } \\
\text { SUV }_{\text {mean }} \\
\end{array}$} & \multicolumn{2}{|c|}{$\begin{array}{c}\text { Bladder } \geq \\
\text { liver } \\
\text { SUV }_{\text {mean }} \\
\end{array}$} \\
\hline & & & & & $n$ & $\%$ & $n$ & $\%$ & $n$ & $\%$ \\
\hline $5(n=128)$ & $0.82(0.84)$ & $1.54(0.38)$ & $2.70(0.60)$ & $6.98(1.47)$ & 17 & 13.2 & 4 & 3.1 & 0 & 0 \\
\hline $17(n=127)^{\star}$ & $3.97(5.03)$ & $1.27(0.36)$ & $2.26(0.52)$ & $6.82(1.44)$ & 100 & 78.7 & 75 & 59.1 & 18 & 14.2 \\
\hline $29(n=125)^{\star}$ & $4.08(4.6)$ & $1.14(0.30)$ & $1.91(0.46)$ & $6.30(1.47)$ & 111 & 92.0 & 84 & 67.2 & 19 & 15.2 \\
\hline
\end{tabular}

*Acquisition halted prematurely in 1 and 3 studies by 17 and 30 min, respectively.

Data in parentheses are SDs.

\section{${ }^{18}$ F-FACBC Synthesis}

${ }^{18}$ F-FACBC was synthesized at an institutional or central radiopharmacy through previously reported automated radiosynthesis methods or via a cassette produced by GE Healthcare into a synthesis module (FastLab) (22).

\section{Details of ${ }^{18} \mathrm{~F}$-FACBC Scans}

Details of most of the clinical study protocols and acquisition parameters have been previously reported (5-14,23). PET/CT was performed on a Discovery DLS, DST, STE, or MV690 (GE Healthcare); a TruePoint Biograph 6 or Biograph mCT 40 (Siemens Medical Solutions); or a Gemini TF scanner (Philips Healthcare), except for the scans of 18 patients acquired on a PET-only Siemens ECAT 921. PET and CT acquisition parameters were specific to the PET device and protocol and ranged from dynamic acquisition in list mode to 2- to 4-min static time frames using either 2- or 3-dimensional mode and filtered backprojection or iterative reconstruction. All patients fasted for $4 \mathrm{~h}$ or longer before the study.

\section{Image Analysis}

Images were reviewed on MIMvista (MIMSoftware), Xeleris (GE Healthcare), Syngo Multimodality Volumetric Analysis (Siemens Medical Solutions), or PMOD 3.1 (PMOD Technologies) workstations. Studies were examined qualitatively, though supplemented with quantitative data from prior and ongoing analyses, such as bladder activity data collected for Table 2 and published dosimetry data $(9$, 20,21 ). For descriptive purposes in this paper, mild uptake is defined as equal to or greater than blood pool but less than marrow, moderate as equal to or greater than marrow but less than liver, and intense as equal to or greater than liver. Absent uptake or uptake less than blood pool is described as such. Reference mean standardized uptake values $\left(\mathrm{SUV}_{\text {mean }}\right)$ for blood pool, marrow, and liver at varying time points from a subanalysis of a 128-study cohort are provided in Table 2.

\section{RESULTS}

\section{Physiologic Uptake Patterns}

Cerebrum, Head, and Neck. Brain parenchyma demonstrated uptake less than blood pool, though brain conspicuity slightly increased with time. Moderate pituitary uptake, which decreased with time, was present in more than $90 \%$ of patients. The scalp was seen as a separate structure covering the skull. Salivary glands and lymphoid tissue of Waldeyer's ring had moderate symmetric uptake, also decreasing with time. Thyroid tissue had mild activity. Figure $1 \mathrm{~A}$ is an example of a whole-body early acquisition from a
${ }^{18} \mathrm{~F}-\mathrm{FACBC}$ scan for recurrent prostate cancer, and Figure $1 \mathrm{~B}$ is a dedicated acquisition of the head and neck region.

Chest. After initial blood pool diminished, mild to moderate uptake in the myocardium became evident and increased in a manner similar to muscle. Lung parenchyma demonstrated absent uptake or uptake less than blood pool. Breast parenchyma had mild ${ }^{18}$ F-FACBC uptake but absent uptake or less than blood pool with increasing fatty change. Some degree of mild to moderate diffuse esophageal uptake was seen in more than $50 \%$ of patients (Fig. 2). Though the relationship of this activity to reflux disease has not been formally studied, the pattern was similar to that seen with inflammatory reflux with ${ }^{18}$ F-FDG PET, more frequently involving the distal esophagus and gastroesophageal junction.

Abdomen and Pelvis. The liver and pancreas were most intense on ${ }^{18}$ F-FACBC (Fig. 2). Pancreatic activity was greater than that of liver initially, but by $15 \mathrm{~min}$ pancreatic uptake diminished to or

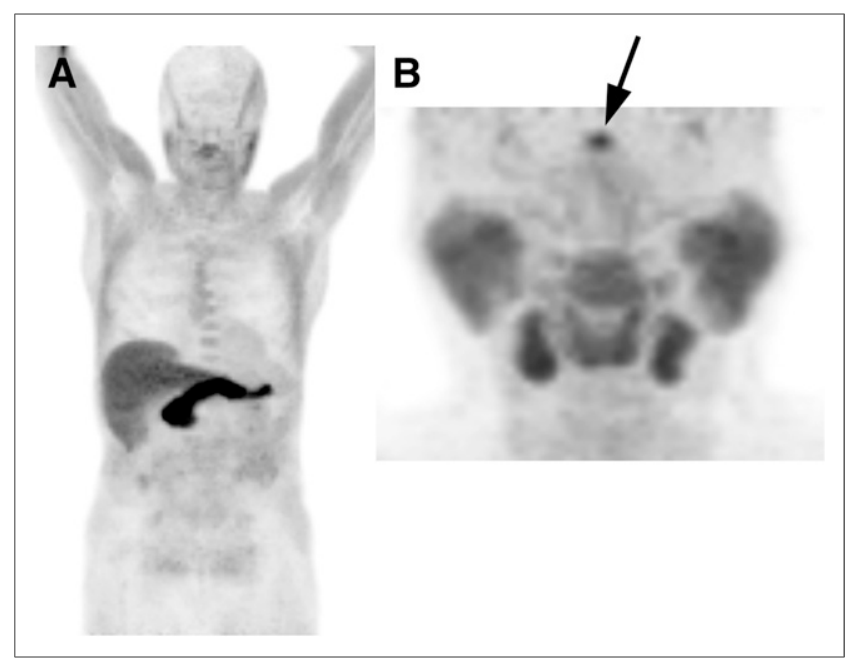

FIGURE 1. (A) Early-time-point ${ }^{18} \mathrm{~F}-\mathrm{FACBC}$ maximum-intensity-anterior projection (MIP) demonstrates intense liver and pancreatic uptake, cerebral and lung uptake less than blood pool, and absent urinary excretion. Greater muscle uptake is noted in upper body because scanning proceeded caudal to cranial, and muscle uptake increased with time. (B) MIP from different patient in dedicated head and neck study demonstrates moderate uptake in salivary glands, lymphoid tissue of Waldeyer's ring, and pituitary activity (arrow). 


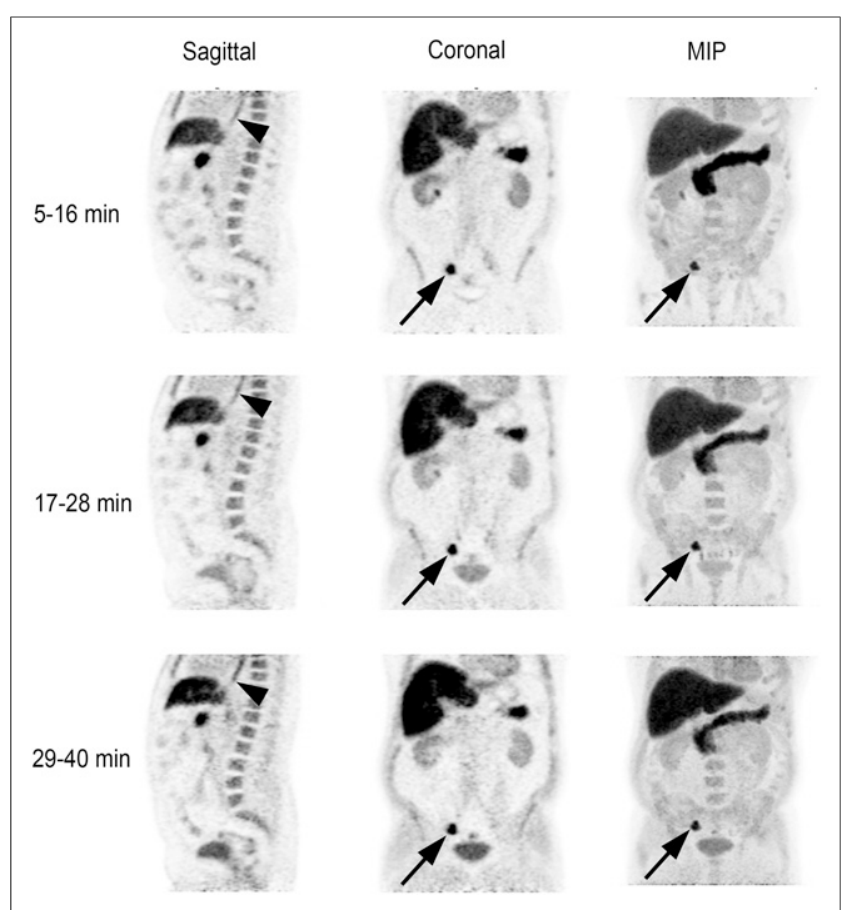

FIGURE 2. Sagittal, coronal, and maximum-intensity-projection (MIP) ${ }^{18} \mathrm{~F}-\mathrm{FACBC}$ images acquired over 3 time intervals $(5-16,17-28$, and 29 $40 \mathrm{~min}$ ) in patient with recurrent prostate cancer. Images demonstrate common appearance of background organ structures as described in text. Uptake is noted in right iliac nodes (arrows) at site of metastatic recurrent prostate carcinoma. Bladder activity initially is absent but moderately increases with time. Also noted is mild to moderate diffuse esophageal activity (arrowheads).

below that of liver. The spleen and renal parenchyma had mild to moderate ${ }^{18} \mathrm{~F}-\mathrm{FACBC}$ uptake. More intense excreted activity might be present in the proximal collecting system. The adrenals also had mild uptake, but in approximately $10 \%$ of patients moderate to intense unilateral or bilateral adrenal uptake might be seen, which does not seem to correlate with the presence of pathology. Variable mild to moderate gastric, bowel, and colonic uptake was also observed.

Bladder activity was typically absent or less than blood pool on early images but might be mild to moderate in $10 \%-15 \%$ of patients. In our experience, ${ }^{18} \mathrm{~F}$-FACBC excretion and resultant focal bladder activity may interfere with the evaluation of adjacent prostate bed and seminal vesicles in 5\%-10\% of early images in some patient cohorts and may be related to diuretic load from intravenous contrast given as part of a CT protocol. Mild diffuse uptake in the bladder wall has also been observed on early sequences. Table 2 contains data from a subanalysis of 128 studies describing bladder activity.

The prostate had mild uptake, though this requires further validation because most studies have been in patients with prostate cancer. The urethral region demonstrated mild ${ }^{18}$ F-FACBC uptake in a linear configuration. Because of limited experience with pelvic imaging in women, no descriptions of normal pre- or postmenopausal uterus or ovaries could be offered.

Musculoskeletal System. The marrow demonstrated moderate and frequently somewhat heterogeneous or patchy ${ }^{18} \mathrm{~F}-\mathrm{FACBC}$ uptake, which decreased over time and appeared to correlate with expected locations of red marrow (Fig. 2). Heterogeneous bone marrow activity might present a more complex background for the evaluation of bone marrow metastases. Skeletal muscle also had mild uptake initially, which increased with time and surpassed that of marrow at approximately 30-60 min after radiotracer injection (Fig. 1A).

\section{Incidental Findings and Variants}

On the basis of published and unpublished data, ${ }^{18} \mathrm{~F}-\mathrm{FACBC}$ has demonstrated elevated uptake in carcinomas of the prostate, breast, and lung, as well as colonic neoplasia, squamous cell carcinoma of the scalp, follicular lymphoma, multiple myeloma, and primary and metastatic tumors in the brain (Fig. 3) $(5,7,11,14,24)$.

Simple renal cysts do not have ${ }^{18} \mathrm{~F}$-FACBC uptake, in our experience (Fig. 4A). Although papillary cell carcinoma had elevated uptake, clear cell carcinoma had uptake similar to parenchyma (14). As with ${ }^{18}$ F-FDG, any degree of ${ }^{18}$ F-FACBC uptake in a renal mass might represent malignant etiology (Fig. 4B). Benign hepatic cysts and hemangiomas are photopenic, compared with the liver (Fig. 4A).

Postprostatectomy uptake in the urethra might be challenging to differentiate from disease in the prostate bed, but sagittal images aid interpretation (Fig. 5A). Nonmalignant uptake in the prostate might be seen with benign prostatic hyperplasia and acute and chronic inflammation (Figs. 5B and 5C), including after radiation (12,23).

Focal increased uptake in a pituitary adenoma, a meningioma, an osteoid osteoma, and an adrenal gland adenoma has been seen (Fig. 6; written communication from coauthor Trond V. Bogsrud, 2014). ${ }^{18}$ F-FACBC uptake was also observed with both acute and chronic inflammation and infection, including mild to moderate uptake in apparently benign hilar, axillary, and inguinal lymph nodes, which diminished from early to more delayed sequences. Moderate to intense uptake was noted in inflammatory skin lesions, inguinal nodes due to ringworm infection, and musculoskeletal inflammation (Fig. 6; personal observation of first author David M. Schuster, 2008). Mild focal uptake in degenerative facet disease might be seen but not to the same degree as with ${ }^{18} \mathrm{~F}-\mathrm{FDG}$.

\section{DISCUSSION}

${ }^{18} \mathrm{~F}-\mathrm{FACBC}$ is a nonnatural alicyclic amino acid analog PET radiotracer that has in vivo properties similar to its parent compound,

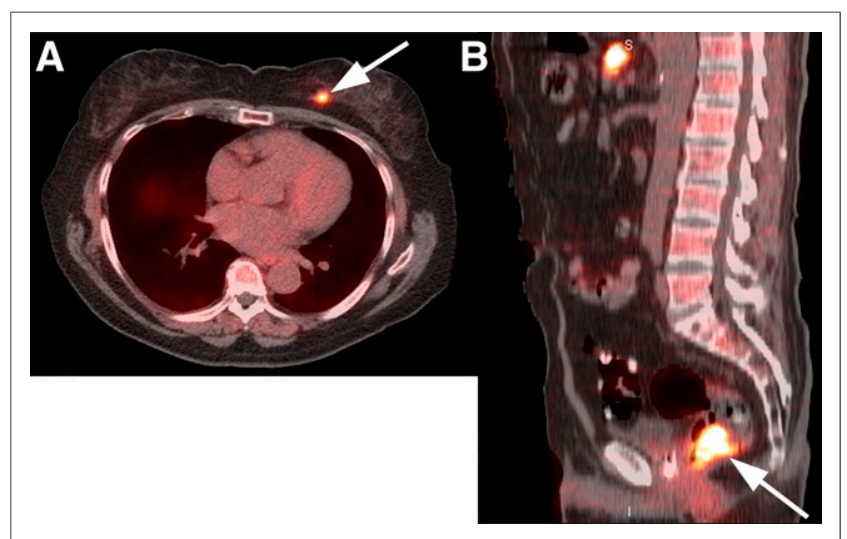

FIGURE 3. (A) Coregistered axial ${ }^{18} \mathrm{~F}-\mathrm{FACBC}$ PET/CT image demonstrates focal uptake in known left breast carcinoma (arrow), but uptake in breast tissue is less than blood pool. (B) Coregistered sagittal ${ }^{18} \mathrm{~F}-\mathrm{FACBC}$ $\mathrm{PET} / \mathrm{CT}$ image shows focal uptake in tubulovillous adenoma (arrow) with atypia, a premalignant tumor, detected incidentally on ${ }^{18} \mathrm{~F}-\mathrm{FACBC}$. 


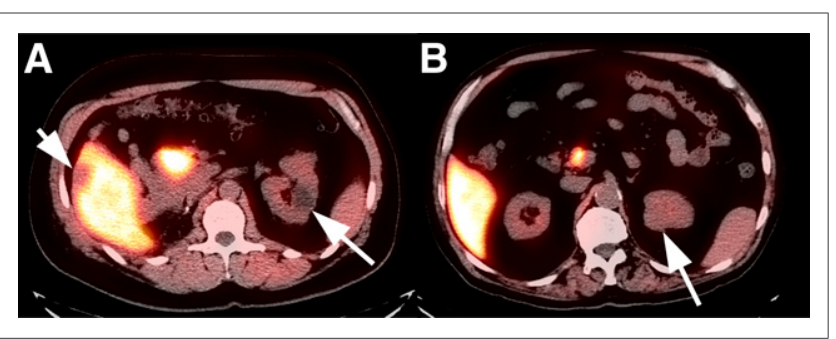

FIGURE 4. (A) Coregistered axial ${ }^{18} \mathrm{~F}-\mathrm{FACBC}$ PET/CT image from summed dynamic ${ }^{18} \mathrm{~F}-\mathrm{FACBC}$ renal study demonstrates lack of uptake in MR imaging-proven hepatic hemangioma (small arrow) and left renal cyst (large arrow). (B) Coregistered axial ${ }^{18} \mathrm{~F}-\mathrm{FACBC}$ PET/CT image demonstrates uptake in renal cancer (arrow) similar to that of renal parenchyma on summed dynamic images.

${ }^{11} \mathrm{C}$-ACBC, yet with the advantage of the 110-min half-life of ${ }^{18} \mathrm{~F}$, facilitating clinical trials for prostate cancer and other neoplasia $(1,6,25)$. Physiologic uptake in small sets of healthy volunteers for dosimetry studies has been described $(9,20,21)$. Because ${ }^{18} \mathrm{~F}$-FACBC is being more widely used, we set out to review patterns of common physiologic activity, variants, and incidental findings based on our collective experience.

We found that uptake patterns were similar to those described for healthy volunteers except for a few minor differences. McParland reported relatively less intense pancreatic uptake, compared with Nye and Asano (9,20,21). Although Asano also described increasing ${ }^{18} \mathrm{~F}-\mathrm{FACBC}$ uptake in muscle over time, there was overall greater muscle activity in the subjects examined by Nye $(9,20)$. Our observations confirmed that pancreatic uptake initially was greater than liver and that muscle uptake increased with time but remained mild to moderate. The variances between these original observations may be secondary to cross-cultural differences in body habitus and diet.

Amino acid-based PET radiotracers target the upregulation of amino acid transporters that occurs in tumors $(2,26)$. The amino acid transporters alanine-serine-cysteine transporter 2 (ASCT2) and L-type amino acid transporter 1 (LAT1) play particularly important roles in tumor amino acid metabolism (26). ${ }^{18} \mathrm{~F}-\mathrm{FACBC}$ is transported primarily by ASCT2 but also with important contributions by LAT1, especially in a dense tumoral cellular environment in which acidic conditions predominate $(15,27,28)$. ASCT2 is a key transporter of glutamine, of which ${ }^{18} \mathrm{~F}-\mathrm{FACBC}$ seems to have the most similarity in terms of transport (16). Glutamine is a critical tumor nutrient for protein synthesis and is also involved in complex cell tumor signaling involving the mammalian/mechanistic target of rapamycin (mTOR) pathway and tricarboxylic acid cycle $(3,29)$. Yet, unlike glutamine, ${ }^{18} \mathrm{~F}-\mathrm{FACBC}$ is not further metabolized.

Amino acids and amino acid transporters are ubiquitous in the body, and it would seem logical that much ${ }^{18} \mathrm{~F}$-FACBC physiologic activity may be explained with this knowledge $(2,4,26,29)$. For example, the pancreas and liver are centers of amino acid metabolism or synthesis of plasma proteins $(4,9,30)$. Increased uptake with certain amino acid radiotracers in the salivary glands, lymphoid tissue, and pituitary seems to be a normal variant $(2,30)$. Muscle is also involved with amino acid metabolism and transport (31). The kidneys contain amino acid transporters such as those used for ${ }^{18} \mathrm{~F}-\mathrm{FACBC}(32) .{ }^{18} \mathrm{~F}-\mathrm{FACBC}$ bladder activity, when present, is mostly derived from the parent ${ }^{18} \mathrm{~F}-\mathrm{FACBC}$ compound having escaped reabsorption and not metabolites (33). If interfering bladder activity is apparent, reimaging prone or after bladder emptying may be of help.
As a synthetic amino acid radiotracer, the physiologic pattern of ${ }^{18} \mathrm{~F}-\mathrm{FACBC}$ distribution in background structures is similar to that of other amino acid PET radiotracers including ${ }^{11} \mathrm{C}$-methionine and $\mathrm{L}-3-{ }^{18} \mathrm{~F}-\alpha$-methyltyrosine $(2,30,34,35)$. Yet some important differences exist. Unlike ${ }^{11} \mathrm{C}$-methionine, ${ }^{18} \mathrm{~F}-\mathrm{FACBC}$ is a nonnatural synthetic amino acid radiotracer that is neither metabolized nor used for protein synthesis (28). Compared with ${ }^{11} \mathrm{C}$-methionine, ${ }^{18} \mathrm{~F}-\mathrm{FACBC}$ demonstrates more rapid pancreatic clearance but comparatively little renal and bladder activity (9). Methionine transport is governed primarily by sodium-independent system $\mathrm{L}$ transporters, whereas ${ }^{18} \mathrm{~F}-\mathrm{FACBC}$ is transported primarily by sodium-dependent system ASC, with lesser contribution by system $\mathrm{L}(15,16,30) .{ }^{18} \mathrm{~F}-\mathrm{FACBC}$ has greater liver uptake and less bladder activity than does $\mathrm{L}-3-{ }^{18} \mathrm{~F}-\alpha$-methyltyrosine, another nonnatural amino acid radiotracer (35). These differences are likely secondary to the presence and density of specific amino acid transporters and other factors such as biologic and electrochemical properties of the ligand, modes of physiologic excretion, and interplay with other nutrient transporters and microenvironments.

Amino acid transport is upregulated in a variety of tumors. Unexpected uptake beyond that ascribed to physiologic activity, especially if focal, intense, and accompanied by an anatomic abnormality on CT, should be further investigated. Though amino acid imaging is believed to be less prone to inflammatory uptake, amino acid transport also occurs in benign inflammation. Uptake of amino acid radiotracers not specific to malignancy has been described, and as demonstrated in this paper, ${ }^{18} \mathrm{~F}-\mathrm{FACBC}$ is no exception $(2,36)$. We have recently shown that although ${ }^{18} \mathrm{~F}-\mathrm{FACBC}$ uptake ratios of tumor cells to activated macrophages and granulocytes are higher than those for ${ }^{18} \mathrm{~F}-\mathrm{FDG}$, the uptake ratios of tumor cells to activated $\mathrm{T}$ and $\mathrm{B}$ cells are comparable (16). Because system A, ASC, or L is overexpressed in activated T or B cells, accumulation of ${ }^{18} \mathrm{~F}$-FACBC in inflammation via these transporters might cause uptake in ${ }^{18} \mathrm{~F}$-FACBC imaging (16).

In the differentiation of benign from malignant uptake in recurrent prostate cancer, Schuster used the prospective criteria of abnormal focal visual and quantitative uptake greater than that of background

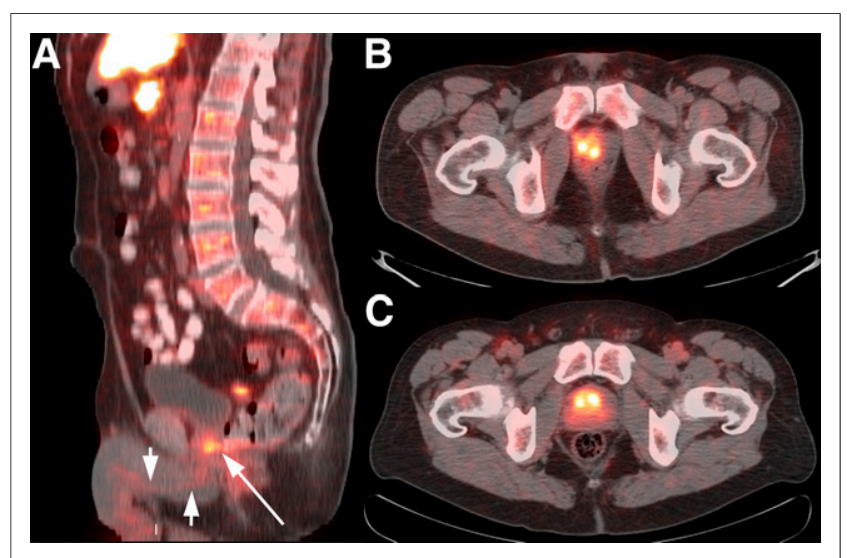

FIGURE 5. (A) Coregistered sagittal ${ }^{18} \mathrm{~F}-\mathrm{FACBC}$ PET/CT image in patient with prostate bed recurrence postprostatectomy. There is mild uptake in urethra (arrowheads) but more focally intense uptake at base of bladder above expected course of urethra in biopsy-proven recurrence (arrow). In addition, uptake is shown in coregistered axial ${ }^{18} \mathrm{~F}$ FACBC PET/CT image for clinically proven prostatitis in healthy volunteer $(B)$ and in patient with benign prostatic hyperplasia (C). 


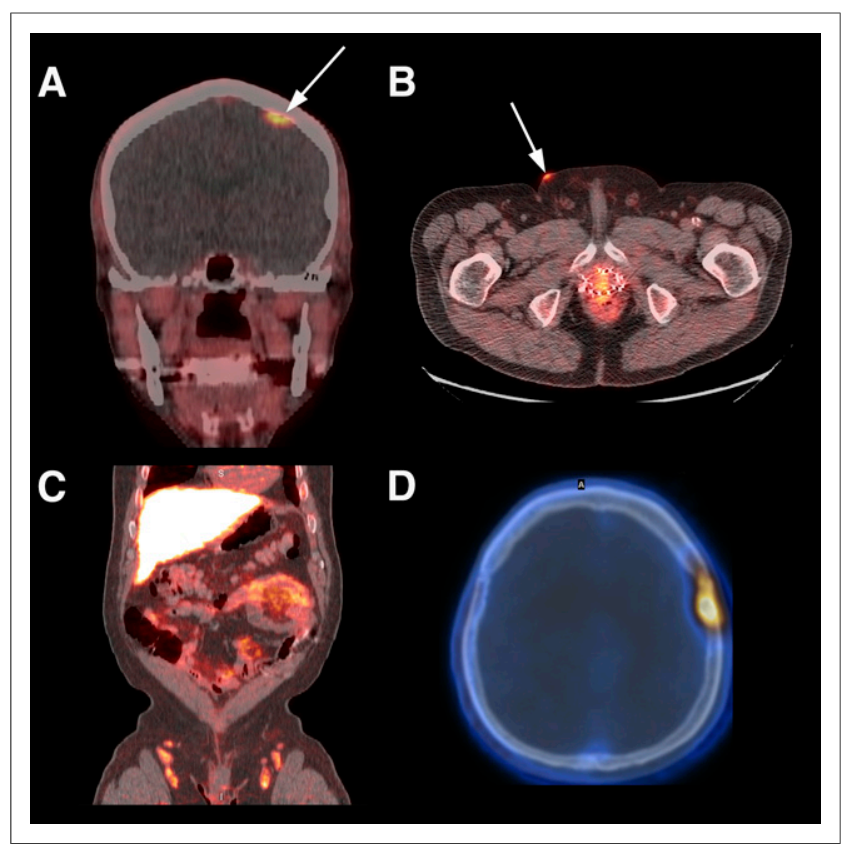

FIGURE 6. Nonmalignant ${ }^{18} \mathrm{~F}-\mathrm{FACBC}$ uptake in coregistered coronal $P E T / C T$ image of meningioma proven on MR imaging (arrow) (A), coregistered axial PET/CT image of inflammatory skin papule (arrow) in patient with recurrent prostate cancer $(\mathrm{B})$, coregistered coronal $\mathrm{PET} / \mathrm{CT}$ image of symmetric inguinal nodes in ringworm infestation as well as physiologic bowel activity (C), and osteoid osteoma on coregistered axial PET/CT image (D).

marrow at L3 persisting from early to delayed imaging using multiphase abdominopelvic acquisitions $(6,13)$. More recently, other groups have reported success with single-time-point whole-body imaging starting from the pelvis $3-5 \mathrm{~min}$ after ${ }^{18} \mathrm{~F}$-FACBC injection (10). Analysis from multiple trials and ongoing consensus development will help standardize scan protocols and interpretative criteria.

The limitations of this investigation include our relatively narrow experience with ${ }^{18} \mathrm{~F}$-FACBC, compared with more commonly used radiotracers such as ${ }^{18} \mathrm{~F}$-FDG. Because most imaging to date has been of men, there are less data for women. Also, there is less experience with certain body regions, such as the head and neck. In addition, most patients studied had cancer, and it is possible that global physiologic patterns involving ${ }^{18} \mathrm{~F}-\mathrm{FACBC}$ are thus altered. Yet, it is reassuring that our observed common physiologic activity patterns are similar to those of healthy volunteers. Finally, this study was not designed as a centralized analysis with definitive follow-up but was intended to be a collective consensus of experience at each site. It is important that such centralized analysis be performed in the future.

\section{CONCLUSION}

The review of studies from multiple ${ }^{18} \mathrm{~F}-\mathrm{FACBC}$ clinical trials demonstrated a common physiologic activity pattern, which included highest intensity in the pancreas and liver. Moderate heterogeneous marrow activity and mild muscle activity were present, with marrow activity decreasing and muscle activity increasing with time. Moderate uptake was noted in salivary, lymphoid, and pituitary tissue, whereas variable mild to moderate activity was present in the bowel. The brain had uptake less than the blood pool. Mild to moderate uptake was present in the kidneys, with absent bladder activity or less than blood pool in early images, though more intense accumulation of excreted activity might occur in a small number of patients. Lack of significant parenchymal uptake in the brain and relatively minimal renal excretion might be advantageous for cerebral and pelvic imaging, respectively. Intense liver and pancreatic uptake would limit disease detection in those organs. Because of efflux of tracer from the tumor, early imaging at less than 30 min was most useful for disease detection. Incidental benign and malignant uptake might occur and should be further evaluated with clinical correlation or other imaging.

\section{DISCLOSURE}

The costs of publication of this article were defrayed in part by the payment of page charges. Therefore, and solely to indicate this fact, this article is hereby marked "advertisement" in accordance with 18 USC section 1734 . Support was provided by the National Institutes of Health (5R01CA129356 and P50 CA 128301); Society of Nuclear Medicine and Molecular Imaging Research and Education Foundation; Nihon Medi-Physics Co., Ltd.; GE Healthcare; Blue Earth Diagnostics Limited; Glenn Family Breast Center Award, Winship Cancer Institute of Emory University; Georgia Cancer Coalition; and Programma di Ricerca Regione (Emilia Romagna)_Università 2010-2012, Bando Giovani Ricercatori. Emory University and Dr. Mark Goodman are eligible to receive royalties for ${ }^{18}$ F-FACBC. Dr. Schuster participates in sponsored research involving ${ }^{18} \mathrm{~F}-\mathrm{FACBC}$ and other radiotracers. No other potential conflict of interest relevant to this article was reported.

\section{ACKNOWLEDGMENTS}

We thank Ronald Crowe RPh, BCNP, and the Emory Center for Systems Imaging Radiopharmacy for assistance on this work.

\section{REFERENCES}

1. McConathy J, Yu W, Jarkas N, Seo W, Schuster DM, Goodman MM. Radiohalogenated nonnatural amino acids as PET and SPECT tumor imaging agents. Med Res Rev. 2012;32:868-905.

2. Jager PL, Vaalburg W, Pruim J, de Vries EG, Langen KJ, Piers DA. Radiolabeled amino acids: basic aspects and clinical applications in oncology. J Nucl Med. 2001;42:432-445.

3. Nakanishi T, Tamai I. Solute carrier transporters as targets for drug delivery and pharmacological intervention for chemotherapy. J Pharm Sci. 2011;100:37313750 .

4. Huang C, McConathy J. Radiolabeled amino acids for oncologic imaging. J Nucl Med. 2013;54:1007-1010.

5. Shoup TM, Olson J, Hoffman JM, et al. Synthesis and evaluation of $\left[{ }^{18} \mathrm{~F}\right] 1-$ amino-3-fluorocyclobutane-1-carboxylic acid to image brain tumors. $\mathrm{J} \mathrm{Nucl} \mathrm{Med}$. 1999;40:331-338.

6. Schuster DM, Nieh PT, Jani AB, et al. Anti-3-[ $\left.{ }^{18} \mathrm{~F}\right] \mathrm{FACBC}$ positron emission tomography-computerized tomography and ${ }^{111}$ In-capromab pendetide single photon emission computerized tomography-computerized tomography for recurrent prostate carcinoma: results of a prospective clinical trial. J Urol. 2014; 191:1446-1453.

7. Amzat R, Taleghani P, Miller DL, et al. Pilot study of the utility of the synthetic PET amino-acid radiotracer anti-1-amino-3- $\left[{ }^{18} \mathrm{~F}\right]$ fluorocyclobutane-1-carboxylic acid for the noninvasive imaging of pulmonary lesions. Mol Imaging Biol. 2013;15:633-643.

8. Sörensen J, Owenius R, Lax M, Johansson S. Regional distribution and kinetics of $\left[{ }^{18} \mathrm{~F}\right]$ fluciclovine (anti- $\left[{ }^{18} \mathrm{~F}\right] \mathrm{FACBC}$ ), a tracer of amino acid transport, in subjects with primary prostate cancer. Eur J Nucl Med Mol Imaging. 2013;40:394-402.

9. Asano Y, Inoue Y, Ikeda Y, et al. Phase I clinical study of NMK36: a new PET tracer with the synthetic amino acid analogue anti-[ ${ }^{18}$ F]FACBC. Ann Nucl Med. 2011;25:414-418. 
10. Nanni C, Schiavina R, Brunocilla E, et al. ${ }^{18}$ F-FACBC compared with ${ }^{11} \mathrm{C}$-choline $\mathrm{PET} / \mathrm{CT}$ in patients with biochemical relapse after radical prostatectomy: a prospective study in 28 patients. Clin Genitourin Cancer. 2014;12: 106-110.

11. Schuster DM, Votaw JR, Nieh PT, et al. Initial experience with the radiotracer anti-1-amino-3- ${ }^{18}$ F-fluorocyclobutane-1-carboxylic acid with PET/CT in prostate carcinoma. J Nucl Med. 2007;48:56-63.

12. Schuster DM, Taleghani PA, Nieh PT, et al. Characterization of primary prostate carcinoma by anti-1-amino-2-[ $\left.{ }^{18} \mathrm{~F}\right]$-fluorocyclobutane-1-carboxylic acid (anti-3$\left[{ }^{18}\right.$ F] FACBC) uptake. Am J Nucl Med Mol Imaging. 2013;3:85-96.

13. Schuster DM, Savir-Baruch B, Nieh PT, et al. Detection of recurrent prostate carcinoma with anti-1-amino-3- ${ }^{18}$ F-fluorocyclobutane-1-carboxylic acid PET/CT and ${ }^{111}$ In-capromab pendetide SPECT/CT. Radiology. 2011;259:852-861.

14. Schuster DM, Nye JA, Nieh PT, et al. Initial experience with the radiotracer anti1-amino-3-[18 F]fluorocyclobutane-1-carboxylic acid (anti-[ $\left.{ }^{18} \mathrm{~F}\right] \mathrm{FACBC}$ ) with PET in renal carcinoma. Mol Imaging Biol. 2009;11:434-438.

15. Oka S, Okudaira H, Yoshida Y, Schuster DM, Goodman MM, Shirakami Y. Transport mechanisms of trans-1-amino-3-fluoro $\left[1-{ }^{14} \mathrm{C}\right]$ cyclobutanecarboxylic acid in prostate cancer cells. Nucl Med Biol. 2012;39:109-119.

16. Oka S, Okudaira H, Ono M, et al. Differences in transport mechanisms of trans1-amino-3- $\left[{ }^{18} \mathrm{~F}\right]$ fluorocyclobutanecarboxylic acid in inflammation, prostate cancer, and glioma cells: comparison with L-[methyl- $\left.{ }^{11} \mathrm{C}\right]$ methionine and 2-deoxy2-[18F]fluoro-D-glucose. Mol Imaging Biol. 2014;16:322-329.

17. Kobayashi K, Bhargava P, Raja S, et al. Image-guided biopsy: what the interventional radiologist needs to know about PET/CT. Radiographics. 2012;32:1483-1501.

18. Bombardieri E, Aktolun C, Baum RP, et al. FDG-PET: procedure guidelines for tumour imaging. Eur J Nucl Med Mol Imaging. 2003;30:BP115-BP124.

19. Kostakoglu L, Hardoff R, Mirtcheva R, Goldsmith SJ. PET-CT fusion imaging in differentiating physiologic from pathologic FDG uptake. Radiographics. 2004;24: 1411-1431.

20. Nye JA, Schuster DM, Yu W, Camp VM, Goodman MM, Votaw JR. Biodistribution and radiation dosimetry of the synthetic nonmetabolized amino acid analogue anti- ${ }^{18}$ F-FACBC in humans. $J$ Nucl Med. 2007;48:1017-1020.

21. McParland BJ, Wall A, Johansson S, Sorensen J. The clinical safety, biodistribution and internal radiation dosimetry of $\left[{ }^{18} \mathrm{~F}\right]$ fluciclovine in healthy adult volunteers. Eur J Nucl Med Mol Imaging. 2013;40:1256-1264.

22. McConathy J, Voll RJ, Yu W, Crowe RJ, Goodman MM. Improved synthesis of anti-[ $\left.{ }^{18} \mathrm{~F}\right] \mathrm{FACBC}$ : improved preparation of labeling precursor and automated radiosynthesis. Appl Radiat Isot. 2003;58:657-666.
23. Turkbey B, Mena E, Shih J, et al. Localized prostate cancer detection with ${ }^{18} \mathrm{~F}$ FACBC PET/CT: comparison with MR imaging and histopathologic analysis. Radiology. 2014;270:849-856.

24. Schuster DM, Votaw JR, Halkar RK, et al. Uptake of the synthetic PET amino acid radiotracer 1 -amino-3- ${ }^{18} \mathrm{~F}$-fluorocyclobutane-1-carboxylic acid $\left({ }^{18} \mathrm{~F}-\mathrm{FACBC}\right)$ within primary and metastatic brain cancer compared with ${ }^{18} \mathrm{~F}$-fluorodeoxyglucose ( ${ }^{18}$ F-FDG) [abstract]. J Nucl Med. 2003;44(suppl):167P.

25. Washburn LC, Sun TT, Byrd B, Hayes RL, Butler TA. 1-aminocyclobutane $\left[{ }^{11} \mathrm{C}\right]$ carboxylic acid, a potential tumor-seeking agent. J Nucl Med. 1979;20:10551061.

26. Fuchs BC, Bode BP. Amino acid transporters ASCT2 and LAT1 in cancer: partners in crime? Semin Cancer Biol. 2005;15:254-266.

27. Okudaira $H$, Nakanishi $T$, Oka $S$, et al. Kinetic analyses of trans-1-amino-3- $\left[{ }^{18} \mathrm{~F}\right]$ fluorocyclobutanecarboxylic acid transport in Xenopus laevis oocytes expressing human ASCT2 and SNAT2. Nucl Med Biol. 2013;40:670-675.

28. Okudaira H, Shikano N, Nishii R, et al. Putative transport mechanism and intracellular fate of trans-1-amino-3- ${ }^{18} \mathrm{~F}$-fluorocyclobutanecarboxylic acid in human prostate cancer. J Nucl Med. 2011;52:822-829.

29. Ganapathy V, Thangaraju M, Prasad PD. Nutrient transporters in cancer: relevance to Warburg hypothesis and beyond. Pharmacol Ther. 2009;121:29-40.

30. Harris SM, Davis JC, Snyder SE, et al. Evaluation of the biodistribution of ${ }^{11} \mathrm{C}$ methionine in children and young adults. J Nucl Med. 2013;54:1902-1908.

31. Drummond MJ, Glynn EL, Fry CS, Timmerman KL, Volpi E, Rasmussen BB. An increase in essential amino acid availability upregulates amino acid transporter expression in human skeletal muscle. Am J Physiol Endocrinol Metab. 2010;298:E1011-E1018.

32. Verrey F, Singer D, Ramadan T. Vuille-dit-Bille RN, Mariotta L, Camargo SM. Kidney amino acid transport. Pflugers Arch. 2009;458:53-60.

33. Amzat R, Faraj B, Nye J, et al. Variable synthetic amino acid radiotracer urinary excretion in prostate carcinoma [abstract]. J Nucl Med. 2012;53(suppl):1096P.

34. Wiriyasermkul P, Nagamori S, Tominaga H, et al. Transport of 3-fluoro-L$\alpha$-methyl-tyrosine by tumor-upregulated L-type amino acid transporter 1: a cause of the tumor uptake in PET. J Nucl Med. 2012;53:1253-1261.

35. Inoue T, Tomiyoshi K, Higuichi T, et al. Biodistribution studies on L-3-[fluorine18]fluoro- $\alpha$-methyl tyrosine: a potential tumor-detecting agent. J Nucl Med. 1998;39:663-667.

36. Plathow C, Weber WA. Tumor cell metabolism imaging. J Nucl Med. 2008;49 (suppl 2):43S-63S 